\title{
STUDIES ON SINGLE AND TWIN PRIME MOVER TRAVELLING WAVE THERMOACOUSTIC SYSTEMS
}

\author{
Vasudevan $\mathrm{K}^{\# 1}$, Shivashankar $\mathrm{R}^{* 2}$, Mathew Skaria ${ }^{\$ 3}$, Shafi K A ${ }^{\$ 4}$, Kasthurirengan $\mathrm{S}^{\# 5}$ \\ ${ }^{\#}$ Centre for Cryogenic Technology, IISc, Bengaluru-560012, India \\ ${ }^{1}$ vasudevabhattar@gmail.com \\ ${ }^{5}$ fantasrini@gmail.com \\ *VidyaVardhaka College of Engineering, Mysuru-570002, India \\ ${ }^{2}$ shivashankar.r@vvce.ac.in \\ ${ }^{\$}$ TKM College of Engineering, Kollam-691005, India \\ 3 mathewskaria@gmail.com \\ ${ }^{4}$ shafika@tkmce.ac.in
}

\begin{abstract}
Experimental and Simulation studies on single prime mover travelling wave thermoacoustic system have been performed for various working fluids such as Argon, Helium etc. at different operating pressures. Then simulation study on twin prime mover travelling wave thermoacoustic system is performed using DeltaEC software where resonators, regenerators, cold heat exchangers, ambient heat exchangers, hot heat exchangers and stack ducts are modeled. The system performance is studied at various operating pressures for various working fluids such as pure gases and binary mixture of helium and Argon. The newly modeled twin prime mover system has better performance in terms of pressure amplitude and resonance frequency when compared to that of a single prime mover travelling wave system. The studies on Helium/Argon mixtures in various proportions as a working fluid in twin prime mover travelling wave system are performed. The helium/Argon mixture at $60 / 40$ ratio proves to be more efficient as its Prandtl number is less. The pressure amplitude of $0.1224 \mathrm{Mpa}$ and frequency of $30 \mathrm{~Hz}$ at 1 Mpa operating pressure is recorded at He/Ar 60/40 ratio mixture.
\end{abstract}

Keyword - DeltaEC, Heat engines, multistage prime movers, Prime movers, Thermoacoustics.

\section{INTRODUCTION}

Thermoacoustic prime movers are of two types, namely standing wave and travelling wave. It is evident from the previous studies and the available literature that travelling wave prime movers performance is better. A single prime mover traveling wave thermoacoustic system is developed and studied in detail. An effort is made to model a twin type (two prime movers in series) travelling wave thermoacoustic prime mover using the DeltaEC modeling software. From the parameter study, such as pressure amplitude and frequency, suitable dimensions for various components are arrived. Then the behavior of the developed model is studied for different operating pressures.

In the year 2011, B. Yu et al. experimentally studied, travelling wave thermoacoustic refrigeration driven by thermoacoustic prime mover, with single prime mover system the operating frequency of $57 \mathrm{~Hz}$ and $3 \mathrm{Mpa}$ pressure could be achieved. In 2013, Bharatbhushan V Kamble et al. studied the performance of twin standing wave thermoacoustic prime mover for pulse tube refrigeration. The work included both experimental as well as the simulation using DeltaEC software and the results were in good match. In the year 2013, N.M. Hariharan et al. studied the effect of resonator length and working fluid on the twin standing wave prime mover. The experimental results were compared with the results of DeltaEC simulation software. M Chen et al. in the year 2013 developed a small scale travelling wave thermoacoustic heat engine with operating frequency of $45 \mathrm{~Hz}$ and with charge pressure of $0.53 \mathrm{Mpa}$. Shinya Hasegawa et al. in the year 2013 developed multistage thermoacoustic engine to drive thermoacoustic refrigerator. In this the temperature required for the engine is considerably less, due to multiple stages. In 2014, Dong-Hui Li et al. developed liquid piston travelling wave thermoacoustic heat engine and studied the behavior with different working fluids. Mathew Skaria et al. developed simulation models for standing wave and travelling wave thermoacoustic prime movers using DeltaEC simulation software and CFD simulation software, the results were matched. Jingyuan $\mathrm{Xu}$ et al. designed and developed double acting thermoacoustic heat engine with operating pressure of $4 \mathrm{Mpa}$ and $300 \mathrm{~Hz}$ as working frequency for thermoacoustic refrigerator. M Chen et al. in the year 2015 studied the effect of working gases on the small thermoacoustic sterling engine. The experimental results were validated with the simulated results of DeltaEc. 


\section{Studies On Single Prime Mover System}

The experimental set up of the Single prime mover system is as shown in Fig 1. The system consists of two parts, a feedback loop and resonator with the buffer. Heater, ambient heat exchanger, stack (made of stainless steel wire mesh), cold heat exchanger, and the compliance tubes are housed in the feedback loop. The heater provides heat energy required to the hot heat exchanger and the cold heat exchanger is circulated with ambient water that can take heat from the other end of the stack. This creates a temperature gradient across the stack, which generates thermoacoustic oscillations. The traveling wave loop is attached with a resonator tube along with the buffer.

To understand the behaviour, the developed travelling wave thermoacoustic prime mover is experimented and performance of the same is studied for various working fluids. The system with similar configuration is modelled using DeltaEC software, the results are compared.

Fig 2 shows resonance frequency of the system measured with different working fluid at different operating pressures. The resonance frequency of the traveling wave system depends on the working fluid. The resonance frequency is independent of operating pressure for a working fluid. As the frequency of oscillation for traveling wave thermoacoustic prime mover is directly proportional to the speed of sound in particular working gas. It is expressed as, " $f=a / 4 \mathrm{~L}$ ", where 'a' is speed of sound and is given by, a $=\sqrt{ }(\gamma(\mathrm{P} / \rho)) \cdot \gamma$ is the ratio of specific heats, $\mathrm{P}$ is the pressure, $\rho$ is the density of working fluid.

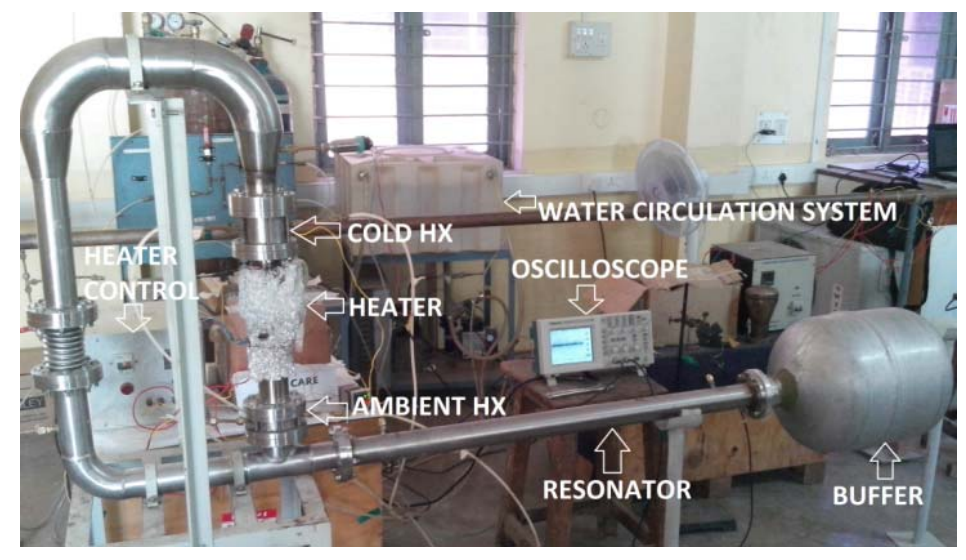

Fig 1. Travelling wave thermoacoustic single prime mover experimental setup.

Increasing the operating pressure correspondingly increases the density of the working gas in the system. So the ratio of working pressure and density remains nearly constant. Hence, the frequency of oscillation is nearly constant with the increase in working pressure. Also Helium shows highest frequency, since the density of gas within the constant volume varies according to the molecular weight. The molecular weight of Helium is low and Argon is high.

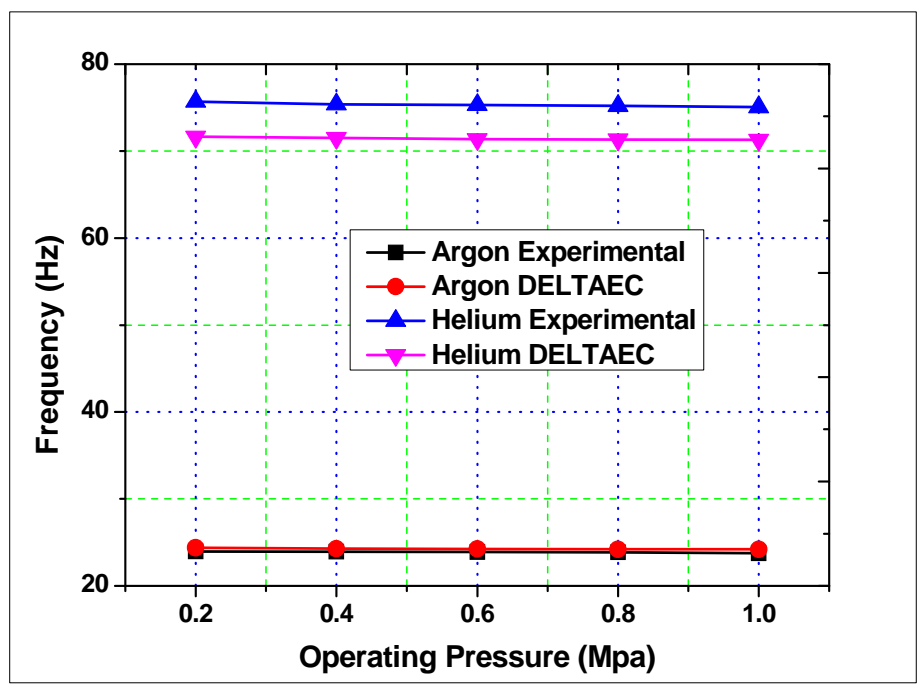

Fig 2. Experimental and simulated frequencies as function of operating pressure. 
Fig 3 shows experimental and simulated pressure amplitude as function operating pressure for Helium and Argon. The pressure amplitude is directly proportional to the operating pressure. This can be attributed as, according to linear thermoacoustics (Swift, 1988) the momentum, continuity and energy equations the pressure amplitude is directly proportional to velocity amplitude by the inertance and viscous resistance. Both inertance and viscous resistance of working gas depend upon the mean density of working gas in the system.

As the operating pressure of the working gas in the system is increased, the density increases correspondingly which leads to the increase in pressure amplitude. Also it is observed that, the pressure amplitude is the highest for Argon, the lowest for Helium. This is because the pressure amplitudes depend on the density of the working gas, and as higher the molecular weight, higher the density causes highest pressure amplitude for Argon as working gas and lowest for Helium due to its lowest density.

Argon shows the highest pressure amplitude at the lowest frequency of $\sim 23 \mathrm{~Hz}$ at an average pressure of 0.51 MPa. On the other hand, Helium shows the lowest pressure amplitude at the highest frequency of $\sim 73 \mathrm{~Hz}$. The reasons for the variation of pressure amplitude with the working fluid have been already explained. The variation in frequency among the working fluids is due to the difference in their molecular weights, which modifies the sound velocity of the fluid.

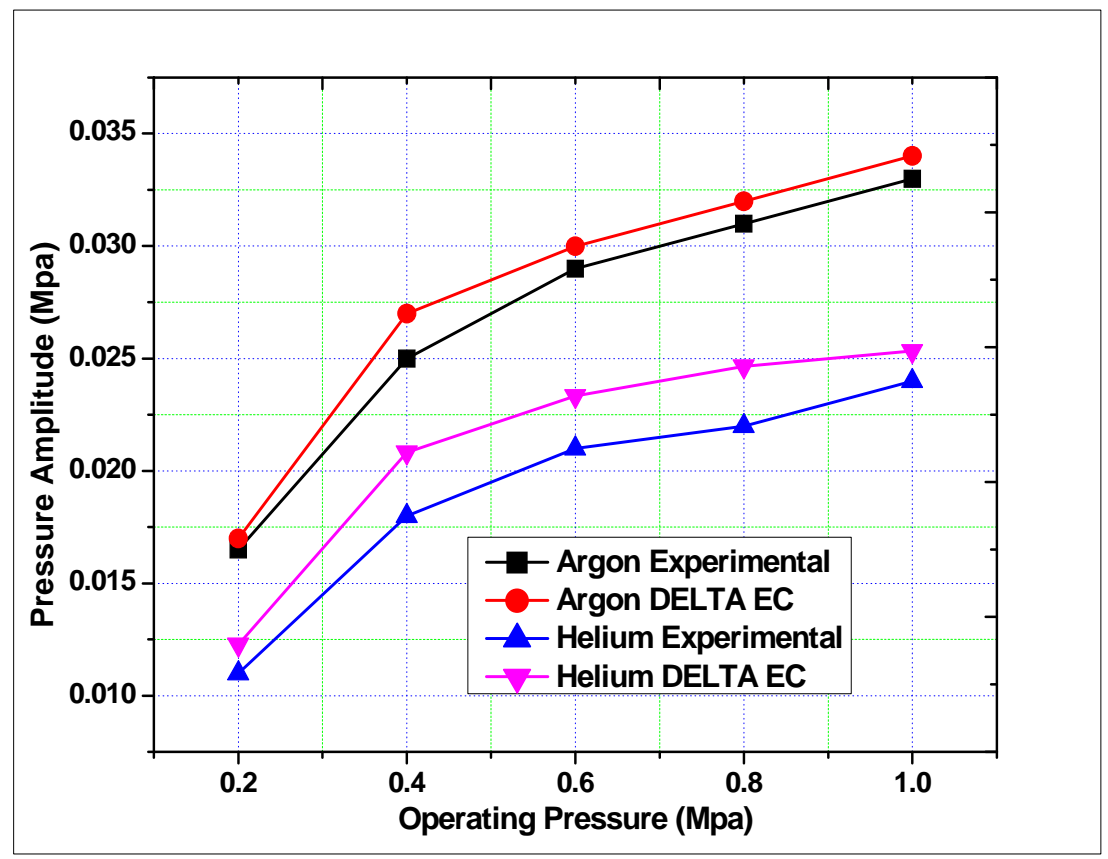

Fig 3. Experimental and simulated pressure amplitudes as function of operating pressure.

\section{DESIGN CONSIDERATIONS FOR MODELLING OF TWIN PRIME MOVER SYSTEM}

- A tube of $50 \mathrm{~mm}$ inner diameter and $57 \mathrm{~mm}$ outer diameter is used for the modelling of the system.

- Initially DeltaEC program is developed for single prime mover system and later extended to desired twin prime mover layout.

- For the purpose of design of independent component, the operating pressure of $10 \mathrm{Mpa}$ is set, with pure Argon as the working fluid.

- Necessary parameters such as porosity of heat exchangers, regenerators, thickness of ducts, length of feedback loop, outline of loops etc. are initially assumed suitably and then modified as per the requirements.

- All specifications such as porosity, radius, gap between the plates in case of heat exchangers, type of meshes in case of regenerators, heat input etc. is exactly similar in both the prime movers. To ensure generation of one single wave with single resonance frequency and pressure amplitude, absolute similarity between the prime movers is required.

- The two prime movers are arranged in series configuration. 


\section{IV.Initial Parameters For Modelling In Deltaec Software}

The following dimensions or specifications are initially used to develop the program of single prime mover system.

TABLE 1. Part Specifications for single prime mover

\begin{tabular}{|l|l|}
\hline \multicolumn{1}{|c|}{ Parts name } & \multicolumn{1}{c|}{ Dimensions } \\
\hline Cold heat exchanger (one in numbers) & $\begin{array}{l}\text { Length }=75 \mathrm{~mm} \\
\text { Porosity }=0.66 \\
\text { Tube Radius }=2 \mathrm{e}-3 \mathrm{~m}\end{array}$ \\
\hline Regenerator (one in numbers) & $\begin{array}{l}\text { Length }=45 \mathrm{~mm} \\
\text { Porosity }=0.66 \\
\text { Hydraulic radius }=1.12 \mathrm{e}-4 \mathrm{~m}\end{array}$ \\
\hline Hot heat exchanger (one in numbers) & $\begin{array}{l}\text { Length }=70 \mathrm{~mm} \\
\text { Porosity=0.66 } \\
\text { Half plate length }=1 \mathrm{e}-3 \mathrm{~m}\end{array}$ \\
\hline $\begin{array}{l}\text { Ambient heat exchanger (one in } \\
\text { numbers) }\end{array}$ & $\begin{array}{l}\text { Length }=45 \mathrm{~mm} \\
\text { Porosity }=0.66 \\
\text { Tube Radius }=2 \mathrm{e}-3 \mathrm{~m}\end{array}$ \\
\hline Stack duct (one in numbers) & $\begin{array}{l}\text { Length }=100 \mathrm{~mm} \\
\text { Wall Area }=8.64 \mathrm{e}-4 \mathrm{~m}^{\wedge} 2\end{array}$ \\
\hline Resonator length & $1 \mathrm{~m}$ \\
\hline
\end{tabular}

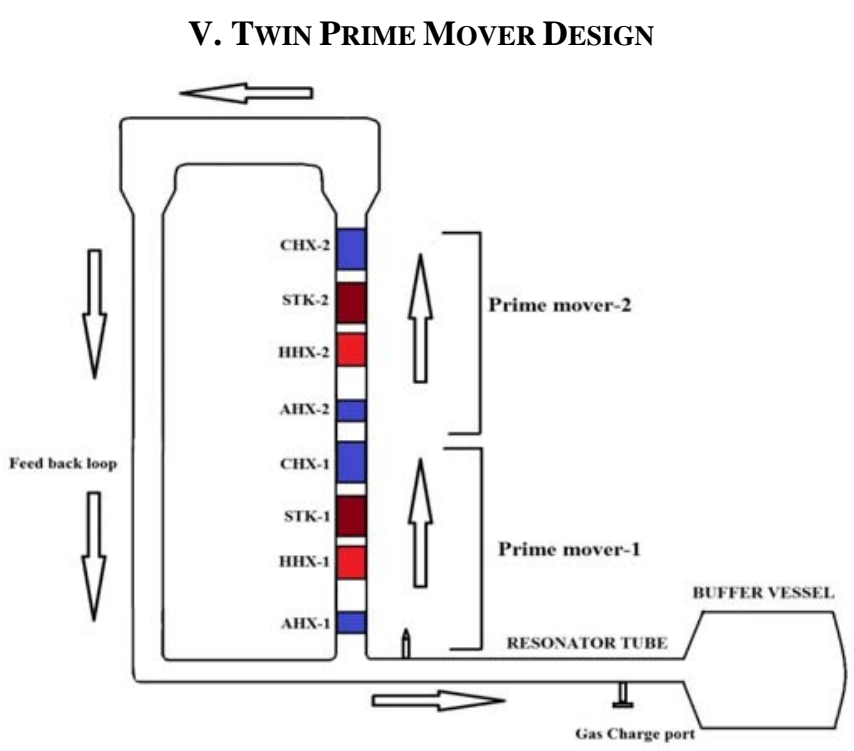

Fig 4. Design layout of twin prime mover system

\section{A. Design of resonator tube}

The resonator tube is the important component, by varying which both the resonance frequency as well as pressure amplitude varies. The resonator tube material is selected as stainless steel. The inner diameter of the resonator is taken as $50 \mathrm{~mm}$. The outer diameter is $57 \mathrm{~mm}$, with $3.5 \mathrm{~mm}$ wall thickness. This decides cross sectional area of resonator through which fluid can flow. The Srough is inner surface roughness of the tube or duct, whose value is $6 \mathrm{e}-4$ for turbulent dissipation of fluids. The appropriate length for the resonator has to be arrived. The variation of pressure amplitude and resonance frequency with the resonator length is plotted as shown in fig 4.

The pressure amplitude of the system increases almost linearly with resonator length and reaches maximum value of $0.1498 \mathrm{MPa}$ at $2.6 \mathrm{~m}$ then the pressure amplitude decreases. The frequency decreases with increase in resonator length and at $2.6 \mathrm{~m}$ length its value is about $19.5 \mathrm{~Hz}$. The Pressure amplitude has to be as high as possible with minimum resonance frequency for the best performance of the engine. Thus the resonator length of $2.6 \mathrm{~m}$ is arrived from the above graphs. 


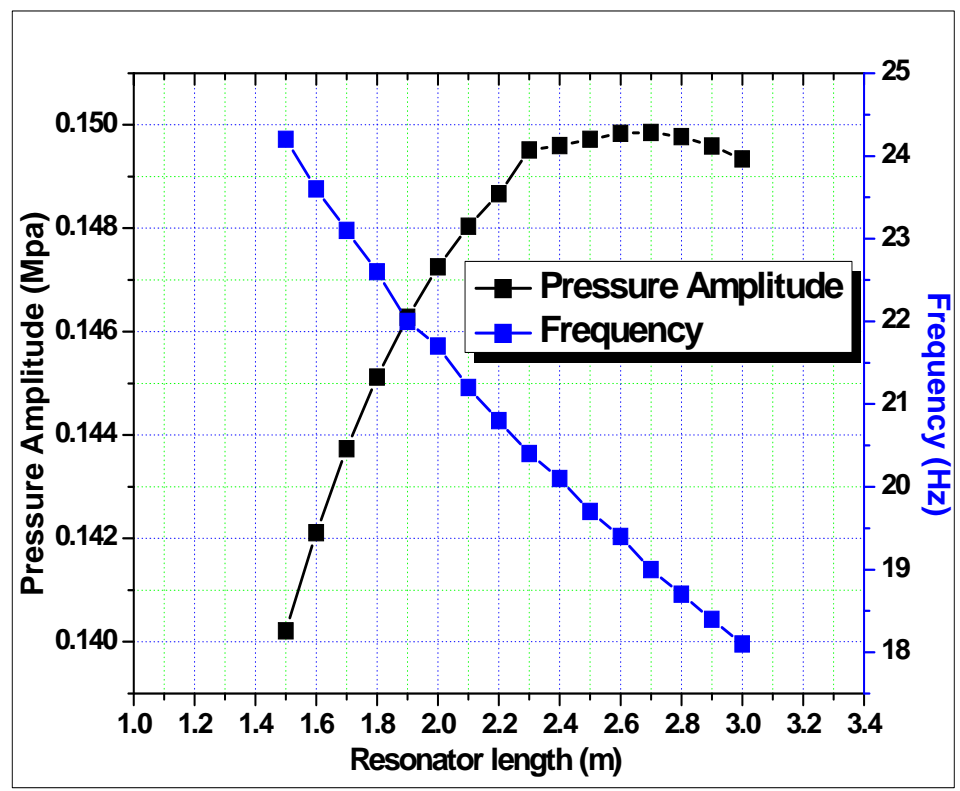

Fig 5. Pressure amplitudes and frequencies verses resonator length.

\section{B. Design of cold heat exchangers}

The cold heat exchangers are placed right below the regenerator. The working fluid moves inside small cylindrical holes of given porosity. It is made of copper, as it is a good conductor. There are two cold heat exchangers in twin prime mover system. A water jacket arrangement is made externally to circulate water at room temperature around the heat exchangers. The water pumping arrangements are made for continuous circulation of water. The diameter of the heat exchanger remains same as that of the inner diameter of the resonator tube; the length of the heat exchangers has to be determined. The graph shows the variation of pressure amplitude and frequency with heat exchanger length.

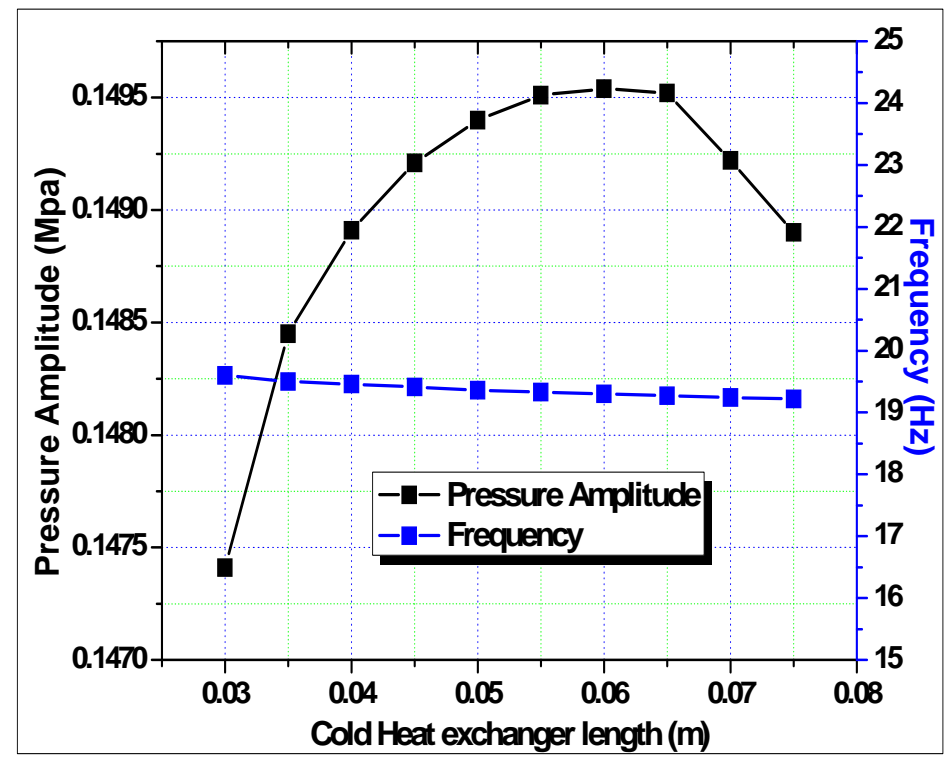

Fig 6. Pressure amplitudes and frequencies verses cold heat exchanger length

The pressure amplitude increases with the length of cold heat exchanger, reaches a stable value at $0.055 \mathrm{~m}$ length and then drops. The frequency remains almost constant, with the order of 19-20 Hz. Thus the cold heat exchanger length is taken as $0.055 \mathrm{~m}$.

\section{Design of hot heat exchangers}

This heat exchanger adds heat energy to the working fluid. The twin prime mover system has two hot heat exchangers made of copper. Heater of known power is used externally to supply heat energy. As the heat exchanger length increases, the heat transfer to the working fluid becomes better because of large area of contact, but the pressure amplitude decreases as it acts as the obstruction to the beginning of wave oscillation. So the 
suitable length has to be selected such that the pressure amplitude is not too less and at the same time the operating temperature of the heat exchanger should be less than the melting point of the copper. The graph shows the variation of pressure amplitude and frequency with respect to the length of hot heat exchanger.

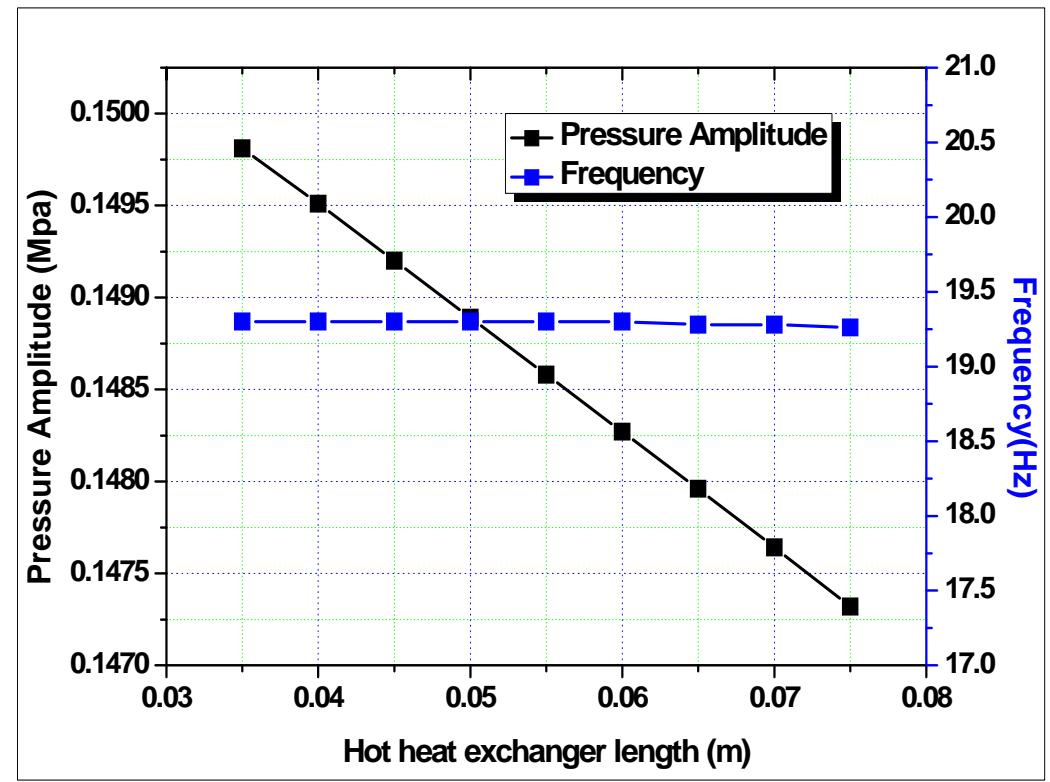

Fig 7. Pressure amplitudes and frequencies verses hot heat exchanger length.

Pressure amplitude decreases with length of hot heat exchanger up to $0.075 \mathrm{~m}$. The frequency being $19-20 \mathrm{~Hz}$ remains almost constant with increase in length of hot heat exchanger. At $0.065 \mathrm{~m}$ length of the hot heat exchanger, pressure amplitude is about $0.1480 \mathrm{Mpa}$. The length of $0.065 \mathrm{~m}$ is an optimum value as the temperature remains well within the limit.

D. Design of ambient heat exchangers

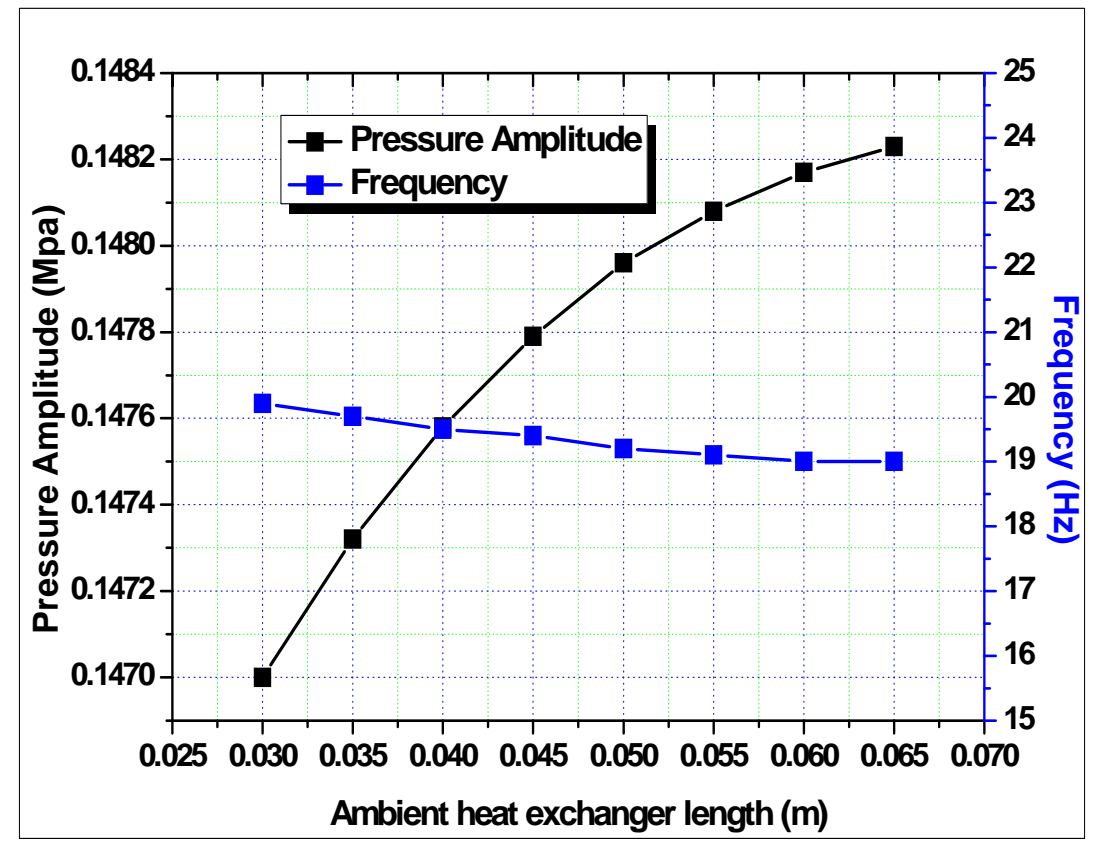

Fig 8. Pressure amplitudes and frequencies verses ambient heat exchanger length.

Ambient heat exchangers are required to stabilize flow of the working fluid and to reduce the temperature of working fluid, thus preventing the temperature rise of the working fluid and the system. The two ambient heat exchangers are used in twin prime mover system. The graphs show the variation of pressure amplitude and frequency with length of ambient heat exchanger. 


\section{E. Design of regenerator}

The twin prime-mover system contains two regenerators of wire mesh type. The regenerators are made of stainless steel mesh. As the length of the regenerator increases pressure amplitude increases and frequency remains constant. The temperature gradient is maintained across the regenerators.

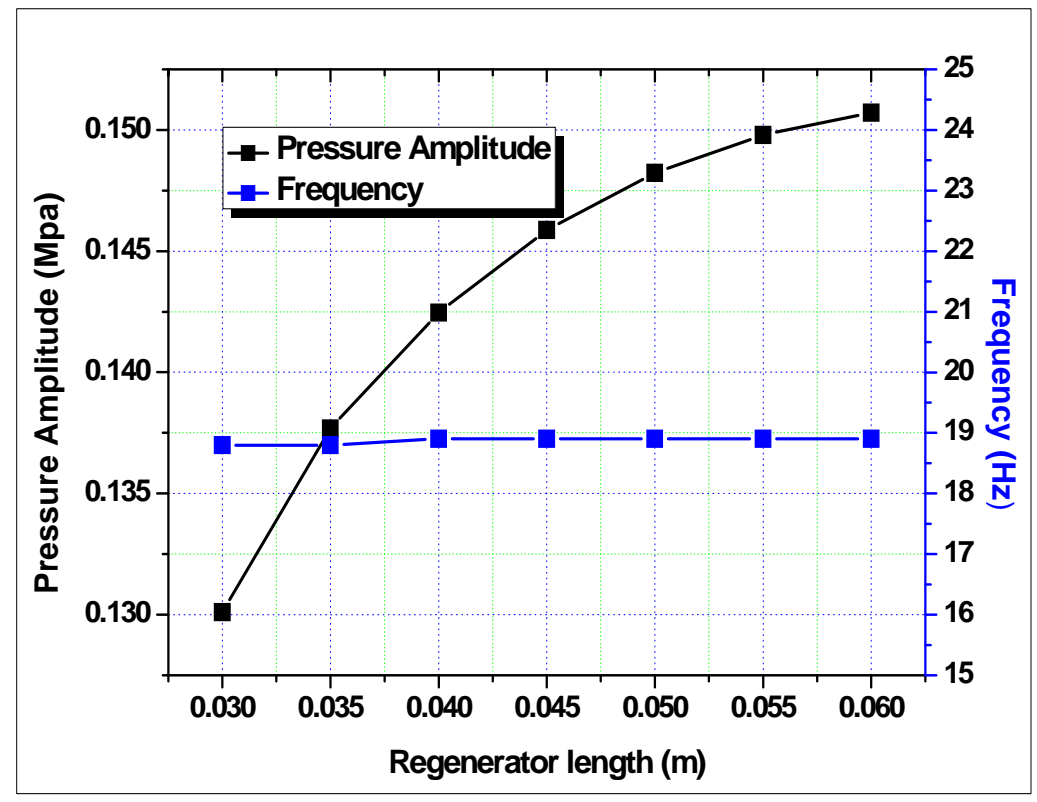

Fig 9. Pressure amplitudes and frequencies verses regenerator length.

The regenerator is placed between cold and hot heat exchangers, whose lengths are $0.055 \mathrm{~m}$ and $0.065 \mathrm{~m}$ respectively. From the above graph, the appropriate length of regenerator is taken as $0.05 \mathrm{~m}$. The other parameters are mesh type $\mathrm{N}=30$, Porosity $=0.74$, and hydraulic radius $\mathrm{Rh}=199.2 \mathrm{e}-6 \mathrm{~m}$.

\section{F. Design of stack duct}

This duct decides the position of the prime movers and ambient heat exchangers. Increase in the length of this corresponds to increase in pressure amplitude and frequency remains almost constant. But the temperature of hot heat exchanger increases. The graphs show the variation of the amplitude and frequency with the length of stack.

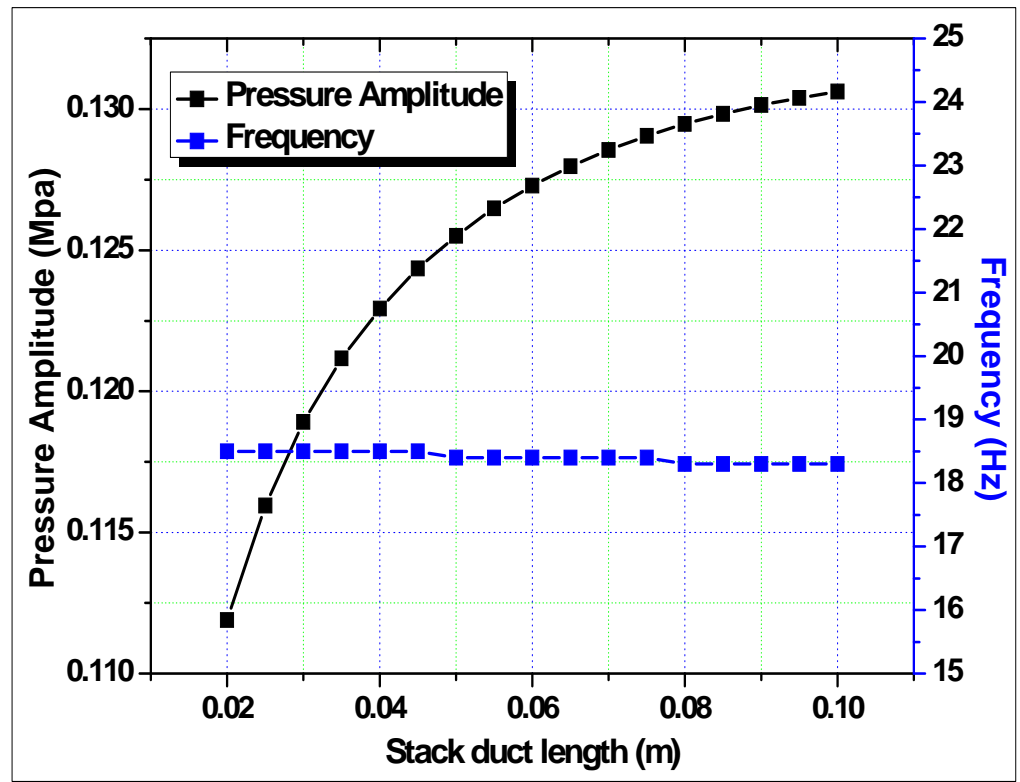

Fig 10. Pressure amplitudes and frequencies verses stack duct length.

From the above graphs the appropriate value for the length of stack duct appears to be $0.1 \mathrm{~m}$. The wall area is $8.64 \mathrm{e}-4 \mathrm{~m}^{2}$ corresponds to the wall thickness of $0.05 \mathrm{~m}$. 


\section{Design Parameters Arrived From Deltaec Software}

From DeltaEC software, specific design dimensions for twin prime mover system are arrived as shown.

TABLE II. Part Specifications for twin prime mover

\begin{tabular}{|l|l|}
\hline \multicolumn{1}{|c|}{ Parts name } & \multicolumn{1}{c|}{ Dimensions } \\
\hline Cold heat exchanger (two in numbers) & $\begin{array}{l}\text { Length }=55 \mathrm{~mm} \\
\text { Porosity=0.66 } \\
\text { Tube Radius=2e-3m }\end{array}$ \\
\hline Regenerator (two in numbers) & $\begin{array}{l}\text { Length }=55 \mathrm{~mm} \\
\text { Porosity=0.74 } \\
\text { Hydraulic radius=1.99e-4m }\end{array}$ \\
\hline Hot heat exchanger (two in numbers) & $\begin{array}{l}\text { Length }=65 \mathrm{~mm} \\
\text { Porosity=0.66 } \\
\text { Half plate length=1e-3m }\end{array}$ \\
\hline $\begin{array}{l}\text { Ambient heat exchanger (two in } \\
\text { numbers) }\end{array}$ & $\begin{array}{l}\text { Length=65mm } \\
\text { Porosity=0.66 } \\
\text { Tube Radius }=2 \mathrm{e}-3 \mathrm{~m}\end{array}$ \\
\hline Stack duct (three in numbers) & $\begin{array}{l}\text { Length=100mm } \\
\text { Wall Area }=8.64 \mathrm{e}-4 \mathrm{~m}^{\wedge} 2\end{array}$ \\
\hline Resonator length & $2.6 \mathrm{~m}$ \\
\hline
\end{tabular}

\section{Vi.Simulation Results Of Twin Prime Mover System}

The Fig 11 and 12 show variation of resonance frequency and pressure amplitude with operating pressure respectively, for pure gases and binary mixtures of helium and Argon. The resonance frequency is independent of operating pressure. The pressure amplitude increases with operating pressure. The frequency of helium gas is higher than argon because of its low molecular weight.

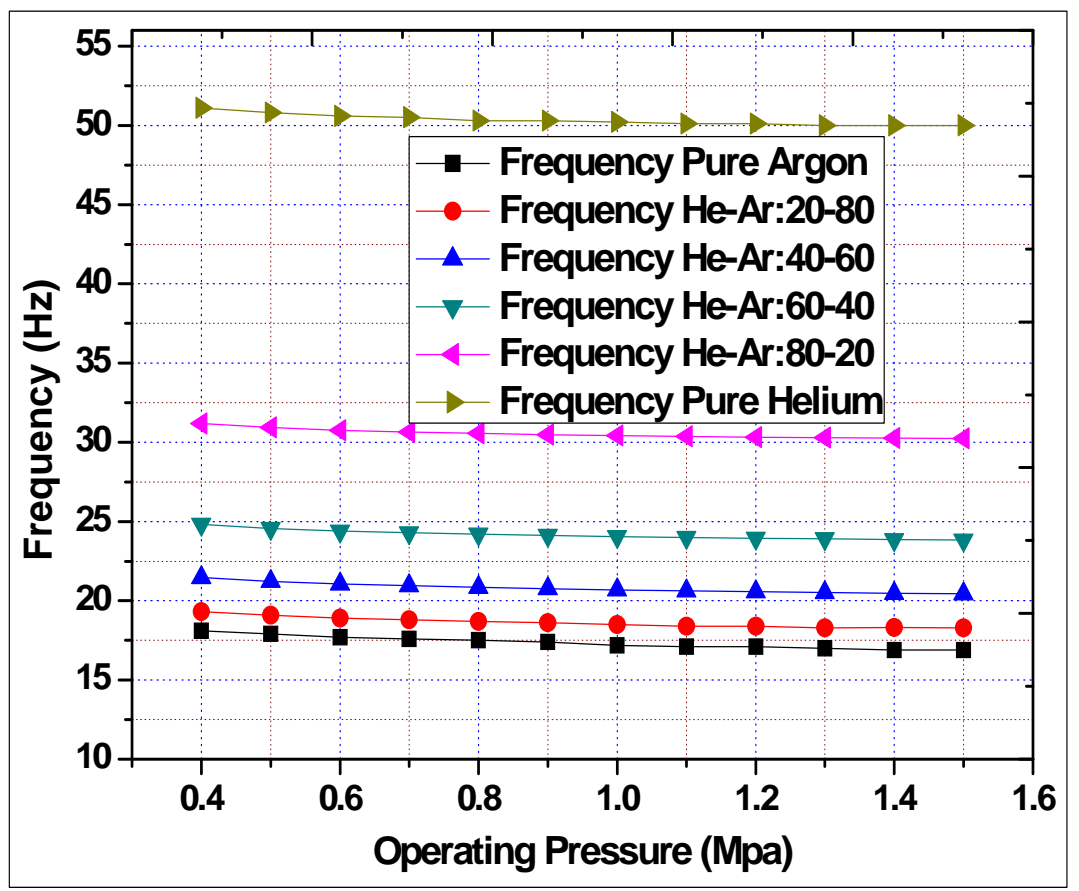

Fig 11. Simulated results of resonance frequencies verses operating pressure.

The pressure amplitude of Argon is higher, as it has higher molecular weight than helium. From the above graphs, it is evident that the pressure amplitude is high for Argon with low resonance frequency, but the required temperature gradient across the regenerator for the beginning of the oscillation is very high. On other hand helium requires low temperature gradient to produces low pressure amplitude and high resonance frequency waves. 


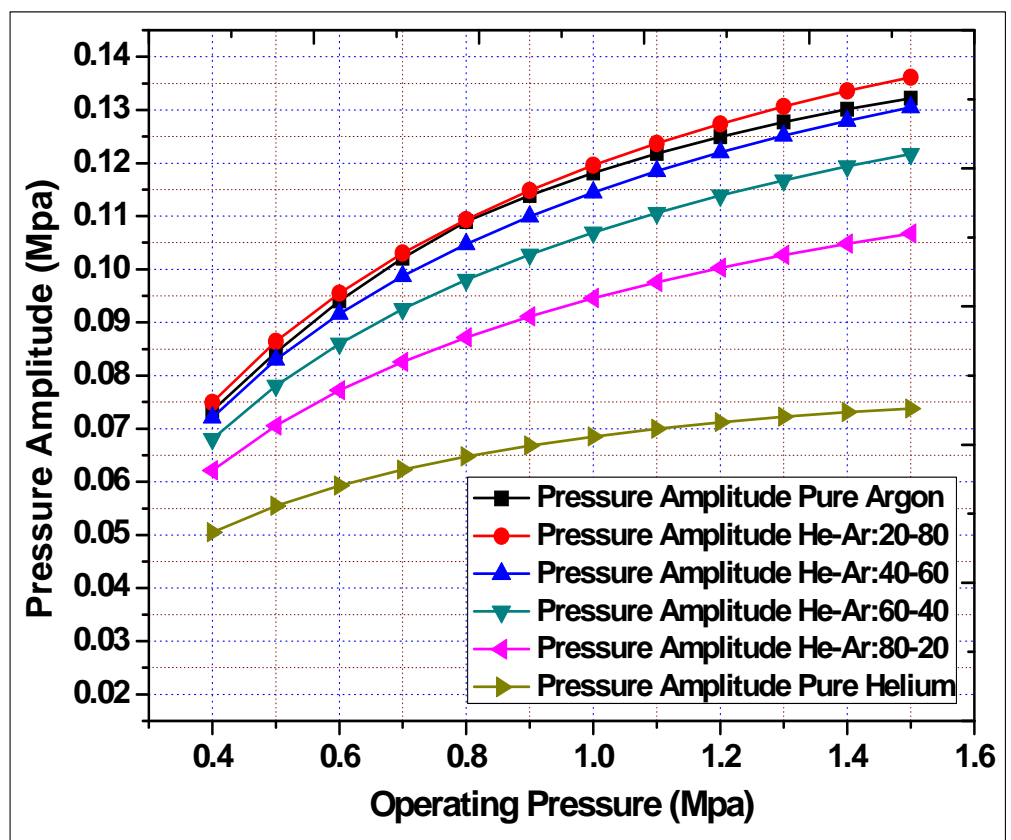

Fig 12. Simulated results of pressure amplitudes verses operating pressure.

A mixture of helium and argon in appropriate proportion will result in good pressure amplitude and frequency, operating at less temperature gradient when compared to pure gases. The pressure Amplitude and frequency of binary mixtures are plotted and it is evident from the graphs that the He/Ar mixture of 60/40 ration is optimum. The fluids with very low value of Prandtl number acts as best thermoacoustic fluid. The Prandtl number for HeAr mixture of 60-40 ratio is least among all other mixtures thus acts as the best thermoacoustic working fluid. The same can be even visualized by simulation results.

\section{CONCLUSIONS}

The Delta Ec modelling and simulation has been performed for single prime mover system, the results fairly matched with the experimental results. Then simulation study on twin prime mover system has been performed. The frequency of working fluid is almost independent of operating pressure. The pressure amplitude increases with operating pressure attains maximum value and then decreases. The DeltaEC successfully predicts the values of pressure amplitude and frequency, but fails to predict the $\mathrm{T}$ begin value. Among all the working fluids, binary mixture of $\mathrm{He} / \mathrm{Ar}$ at 60/40 ratio acts as the best fluid due to its low Prandtl number, gives an intermediate optimum frequency and with considerably good pressure amplitude.

\section{NOMENCLATURE}

$\begin{array}{ll}\text { HX } & \text { Heat exchanger } \\ \text { HHX-1 } & \text { Hot heat exchanger of first prime mover } \\ \text { CHX-1 } & \text { Cold heat exchanger of first prime mover } \\ \text { STK-1 } & \text { Regenerator of first prime mover } \\ \text { AHX-1 } & \text { Ambient heat exchanger of first prime mover } \\ \text { HHX-2 } & \text { Hot heat exchanger of second prime mover } \\ \text { CHX-2 } & \text { Cold heat exchanger of second prime mover } \\ \text { STK-2 } & \text { Regenerator of second prime mover } \\ \text { AHX-2 } & \text { Ambient heat exchanger of second prime mover } \\ \text { Delta T1 } & \text { Temperature gradient across regenerator-1 } \\ \text { Delta T2 } & \text { Temperature gradient across regenerator-2 }\end{array}$

\section{REFERENCES}

[1] B. Yu, E.C. Luo, S.F. Li, W. Dai, Z.H. Wu, "EXPERIMENTAL STUDY OF A THERMOACOUSTICALLY-DRIVEN TRAVELING WAVE THERMOACOUSTIC REFRIGERATOR”, Cryogenics 51, 2011; 49-54.

[2] Bharatbhushan V. Kamble, Biju T. Kuzhiveli, S. Kasthurirengan , UpendraBehera, "EXPERIMENTAL AND SIMULATION STUDIES ON THE PERFORMANCE OF STANDING WAVE THERMOACOUSTIC PRIME MOVER FOR PULSE TUBE REFRIGERATOR", International journal of refrigeration 36, 2013; 2410-2419. 
[3] N.M. Hariharan a, P. Sivashanmugam a, S. Kasthurirengan, "EFFECT OF RESONATOR LENGTH AND WORKING FLUID ON THE PERFORMANCE OF TWIN THERMOACOUSTIC HEAT ENGINE - EXPERIMENTAL AND SIMULATION STUDIES", Computers \& Fluids 75, 2013; 51-55.

[4] M. Chen, Y.L. Ju, "DESIGN AND EXPERIMENTAL INVESTIGATIONS ON A SMALL SCALE TRAVELING WAVE THERMOACOUSTIC ENGINE", Cryogenics 54, 2013; 10-15.

[5] Shinya Hasegawa, Tsuyoshi Yamaguchi, YasuoOshinoya, "A THERMOACOUSTIC REFRIGERATOR DRIVEN BY A LOW TEMPERATURE DIFFERENTIAL, HIGH-EFFICIENCY MULTISTAGE THERMOACOUSTIC ENGINE”, Applied Thermal Engineering, 58, 2013; 394-399.

[6] Dong-Hui Li, Yan-Yan Chen, Er-Cang Luo, Zhang-Hua Wu, "STUDY OF A LIQUID-PISTON TRAVELING-WAVE THERMOACOUSTIC HEAT ENGINE WITH DIFFERENT WORKING GASES,” Energy 74, 158-163, 2014.

[7] Mathew Skaria, K. K. Abdul Rasheed, K. A. Shafi, S. Kasthurirengan, UpendraBehera, (29 Jan 2014)," IMULATION STUDIES ON THE STANDING AND TRAVELING WAVE THERMOACOUSTIC PRIME MOVERS", Paper presented at AIP Conference Proceedings 1573, 2014:760-767, Advances in Cryogenic Engineering, Anchorage, Alaska, USA, 17-21 June 2013.

[8] Jingyuan Xu, Guoyao Yu, Limin Zhang, Wei Dai, Ercang Luo, Numerical Investigation on a 300Hz Pulse Tube Cryocooler Driven by a Double-acting Thermoacoustic Heat Engine, Energy Procedia, Volume 75, 2015, Pages 1484-1489, ISSN 1876-6102, http://dx.doi.org/10.1016/j.egypro.2015.07.276.

[9] M. Chen, Y.L. Ju, “EFFECT OF DIFFERENT WORKING GASES ON THE PERFORMANCE OF A SMALL THERMOACOUSTIC STIRLING ENGINE", International journal of refrigeration 51, 2015; 41-51.

[10] Tianjiao Bi, ZhanghuaWua, Limin Zhang, Guoyao Yu, Ercang Luo, Wei Dai, "DEVELOPMENT OF A 5 KW TRAVELING-WAVE THERMOACOUSTIC ELECTRIC GENERATOR”, Applied Energy 185 part 2, January 2017; 1355-1361.

[11] Gregory Swift, THERMOACOUSTICS, Springer Handbook of Acoustics, Thomos D Rossing (Ed.): Springer, 2007.

[12] Jia Ren, Ercang Luo, Liming Zhang, Jianying Hu, Wei Dai, "A HIGH-EFFICIENCY TRAVELING-WAVE THERMOACOUSTIC REFRIGERATOR FOR CRYOGENIC COOLING OPERATION: THERMODYNAMIC DESIGN AND PRELIMINARY EXPERIMENT", AIP Conference Proceedings 1434, 343, 2012.

[13] Tao Jin, Jiale Huang, Ye Feng, Rui Yang, Ke Tang, Ray Radebaugh, "THERMOACOUSTIC PRIME MOVERS AND REFRIGERATORS: THERMALLY POWERED ENGINES WITHOUT MOVING COMPONENTS”, Energy 93, 828-853, 2015.

[14] Yu, Z. and Jaworski, A.J. (2010)"IMPACT OF ACOUSTIC IMPEDANCE AND FLOW RESISTANCE ON THE POWER OUTPUT CAPACITY OF THE REGENERATORS IN TRAVELLING-WAVE THERMOACOUSTIC ENGINES”. Energy Conversion and Management, 51(2), pp. 350-359. (doi:10.1016/j.enconman.2009.09.032)

[15] Putnam, A. A, Dennis, W. R, "SURVEY OF ORGAN-PIPE OSCILLATIONS IN COMBUSTION SYSTEMS", Journal of the Acoustical Society of America, 28(2), 246-259, 1956.

[16] Feldman, K. T, "REVIEW OF THE LITERATURE ON SONDHAUSS THERMOACOUSTIC PHENOMENA", Journal of Sound and Vibration 7(1), January 1968; 71-82.

[17] Ceperley P. H., "A PISTONLESS STIRLING ENGINE - THE TRAVELling WAVE HEAT ENGINE", The Journal of the Acoustical Society of America, 66(5): 1508-1513, 1979.

[18] Ward, W. C, Swift, G. W., "DESIGN ENVIRONMENT FOR LOW-AMPLITUDE THERMOACOUSTIC ENGINES", The Journal of the Acoustical Society of America, 95(6), 3671-3672, 1994.

[19] Yazaki T., Iwata A., Maekawa T. And Tominaga A., "TRAVELLINGWAVE THERMOACOUSTIC ENGINE IN A LOOPED TUBE”, Physics Review Letters, 81(15): 3128-3131, 1998.

[20] Backhaus S, Swift G. W, “A THERMOACOUSTIC STIRLING HEAT ENGINE,” Nature 399: 335-338, 1999.

\section{Author ProfiLe}

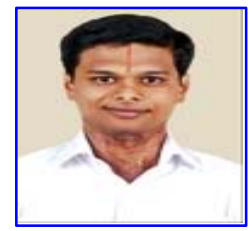

Vasudevan $\mathrm{K}$ is a post graduate in Mechanical engineering with specialization in Machine Design. He is currently working as a Junior Research fellow in a BRNS project at IISc Bengaluru. He has more than two years of research experience in cryogenics and has about 3 research papers to his credit in various Journals. Topic of research includes Pulse tube refrigerators, Thermoacoustics, Emissivity and Thermal conductivity studies, Cryosorption pumps, GM cryocoolers etc.

Shivashankar $\mathrm{R}$ is a post graduate in Mechanical engineering with specialization in Machine Design Engineering. He is currently working as Assistant Professor in the department of mechanical engineering, in Vidyavardhaka college of Engineering, Mysuru. He has almost 7 years of teaching and research experience to his credit with about 6 research papers in various Journals.

Mathew Skaria is working as associate Professor in Mechanical Engineering department at TKM College of Engineering and having more than 16 years of teaching experience. He has published 10 papers in reputed International journals. He has more than 10 years of research experience. His areas of interest are Cryogenics, Thermoacoustics, Thermal sciences, Refrigeration etc.

Shafi K A is working as Professor in Mechanical Engineering at TKM College of Engineering and having more than 22 years of teaching experience. He did his post graduate studies at IIT Madras and PhD at TKMCE in association with IISc Bengaluru. He has published 10 papers in reputed International journals, 15 papers in national journals. He has more than 10 years of research experience. His areas of interest are Cryogenics, Thermal sciences, Refrigeration etc.

Kasthurirengan S started his career after completing Doctorate in Physics in 1975. He has more than 40 years of Experience as a Cryogenic Scientist, at Centre for Cryogenic Technology at the Indian Institute of Science, Bangalore, India. He is currently serving as Professor Emeritus in the department of Cryogenic Technology IISc, Bengaluru. His topics of interest are cryogenics systems, pulse tube coolers etc. 